\title{
Fang Language
}

National Cancer Institute

\section{Source}

National Cancer Institute. Fang Language. NCI Thesaurus. Code C153914.

A Niger-Congo, Bantu language spoken in Cameroon, Gabon, Equatorial Guinea, Sao

Tome and Principe, and the Congo Republic. 